\title{
Performance analysis of the academic units at Universidad Nacional de Córdoba
}

\author{
Catalina Lucía Alberto ${ }^{1}$, Claudia Carignano ${ }^{1}$ \\ ${ }^{1}$ Universidad Nacional de Cordoba, Cordoba, Argentina \\ catalina.alberto@gmail.com, claudiacarignano@gmail.com
}

\begin{abstract}
The Universidad Nacional de Córdoba founded in 1613 is the oldest and one of the largest in the country. In 2011 it had 121,476 undergraduate students, 9,156 teaching positions and 83 degree programs. The university has 13 academic units, two pre-college high schools, two teaching hospitals and a blood lab.

Like any college, the Universidad Nacional de Córdoba aspires to excellence in its core mission: teaching, research and extension. The purpose of this paper is to make a contribution in this direction by analyzing and comparing the performance of academic units between 2007 and 2011. The study uses a nonparametric mathematical programming model, which allows to study the problem in a multiple input - multiple outputs. Variables were considered, the teachers and nonteaching positions, the number of undergraduate students, research projects and undergraduate courses offered by each academic unit.

The results allow comparing the evolution of the performance of each academic unit and provide guidelines to improve the performance of inefficient units.
\end{abstract}

Keywords: National University of Cordoba - Efficiency - DEA models.

\section{Introduction}

The Universidad Nacional de Córdoba (UNC) founded in 1613 is the oldest and one of the largest in the country. In 2011 it had 121,476 undergraduate students, 9,156 teaching positions and 83 degree programs. The university has 13 academic units, two pre-college high schools, two teaching hospitals and a blood lab. As well as the best universities in the world, UNC could also be helped in achieving its goals through a careful planning, a commitment to excellence by teachers, administrative staff and students, and its determination to invest in areas which aim at quality improvement.

Moreover, the external parameters which its programs and activities must be submitted to in order to achieve higher levels of accreditation, financial availability, international associations memberships or rankings presence, are constantly increasing.
With regard to the distribution of the budget, the University lacks a management system able to link the different levels and actors which are relevant to a process of institutional planning. The University Annual Budget is fundamentally made on historical basis, with a clear focus on inputs (means) financing, leaving the expected results (goals) unattended. Thus, there is a "transparent" distribution on its relative loads, which original basis have already lost sustenance or are even unknown, but are still respected as a main guideline and a way to ensure consensus.

Therefore, the budgetary debate usually focuses on annual increases. Those discussions are framed by institutional development objectives previously defined, e.g. growth of public work, care for the new needs demanded by the teachers, scholarships, science and technique. Nevertheless, criteria on which these priorities are set and the resources for each AU or project are finally allocated are not always clear. As a corollary it can be said that there is still much to do in terms of improving budgetary decision making.

The purpose of this paper is to make a contribution in this direction by analyzing and comparing the performance of academic units between 2007 and 2011. A measurement of technical efficiency is proposed, using a nonparametric mathematical programming model (DEA) approach. This scope has been researched by many authors, such as Avkiran (2001), Stern Z., Mehrez A. and Barboy A. (1994), Tomkins C. and Green R. (1988) and Thanassoulis E. and Dunstan P. (1994), among others.

The paper is organized as follows: in section 2 efficiency measurement methods with a frontier approach are described; in section 3, Data Envelopment Analysis (DEA) is presented; in section 4 the variables considered for this study are defined; in section 5 the application to a case study is analyzed; and finally, conclusions are presented in section 6 .

\section{Efficiency Measurement Methods}

The interest in Frontiers of Economic Efficiency analysis has grown rapidly since it arose in the 1950s-1960s, along with several publications about methodologies and applications regarding its estimation. In general, there are 
two main methodologies which were developed for efficiency measure: i) that sustained on econometric techniques; and ii) the one which uses mathematical programming. In both cases, the efficiency of a given productive unit comes from a relative distance measurement with regard to a frontier which is assumed as the maximum limit of efficiency.

On the one hand, the econometric approach specifies a certain formula for the production function, which characterizes the measured productive unit. Efficiency is represented by the distance between the unit and the proposed functional form. This approaching methodology is stochastic and the divergence from the efficiency frontier is considered a product of inefficiency as well as of a random error. In order to measure inefficiency, specific assumptions concerning the functional form of the frontier are imposed, which is a relatively complex process. On the other hand, the mathematical programming approach does not impose a specified structure for the frontier and any deviation is considered an inefficiency. Concerning which methodology is the most adequate, there are different points of view. Some authors adhere to the econometric methods, while others advocate for mathematical programming application. Econometric methods have been criticized for confusing potential efficiency estimates with specification errors, added to its complexity. In contrast, mathematical programming is non-parametric, therefore less susceptible to specification errors. It does not require to assume, a priori, a functional structure of the frontier. It can be objected, however, that it is not able to consider the possibility of deviations that each productive unit may present regarding the efficient frontier, due to entirely random reasons. Punctual efficiency estimates can be obtained from the mathematical programming-based analysis, without being able to examine the accuracy of the estimation and, therefore, not being possible to know if the differences between the compared units are due exclusively to data errors, causing an estimate reliability issue. In order to correct these deficiencies, several analysis alternatives have been proposed with the aim of establishing the sensitivity of the estimates. Among the most widely accepted is the one carried out from a method which has been adapted to approximate the distribution of the efficiency estimator, referred to as DEA methodology, sustained on lineal programming. Beyond all these discussions, versatility and relative easiness of DEA implementation are undeniable.

\section{Data Envelopment Analysis}

DEA is an optimization technique built for measuring the relative efficiency in a group of productive units, known as DMU (Decision Making Units), in the presence of multiple inputs and outputs. DEA provides a method to compare efficiency without the requirement of knowing in advance the production function, i.e., without the necessity to know a functional relation between inputs and outputs.

Generally, efficiency is considered a measure of comparison between inputs, outputs and the ideal values of each one of them. Thereby, comparisons are established between inputs consumed during the production process and the minimum amount required; or between outputs obtained and the maximum achievable. Thus, it is considered a technical efficiency, as known in the literature on the subject. It is said that a unit is technically efficient if it is technologically impossible to increase any output and/or reduce any input without decreasing, at the same time, at least another output and/or without improving at least another input.

In this study, in order to analyze the performance of the academic units, a DEA model with constant returns to scale was applied, as proposed by Charnes, Cooper \& Rhodes (1978), whose formulation is as follows.

$$
\begin{gathered}
\operatorname{Max} \theta=u y^{(0)} \\
\text { s.a. } \\
v x^{(0)}=1 \\
u Y-v X \leq 0 \\
u \geq 0 ; \quad v \geq 0
\end{gathered}
$$

Where,

$u$ an $v$ are the weighs of inputs and outputs, respectively; $x^{(0)}$ and $y^{(0)}$ represent the vector of inputs and outputs, respectively, from the evaluated DMU;

$\mathrm{X}$ and $\mathrm{Y}$ are the inputs and outputs matrixes, whose rows correspond to each DMU;

$\theta$ indicates the value of the index of the evaluated unit.

In order to be considered efficient, a DMU must assure a value of $\theta$ equal to 100 and all the dummy variables of the model must be null.

With the purpose of obtaining efficiency in all the analyzed units.

The model (1) is known as Multipliers Model and its dual receives the name of Envelopment Model. The variables of this model designate the referred units of the $\mathrm{DMU}^{(0)}$ (assessed unit). Moreover, it provides information about potential increases that the DMU should achieve in case it is inefficient, with the aim of improving its performance and projecting toward the frontier.

\section{Variables to be considered in this paper}

Thanassoulis (2001) remarked that "the selection of variables should emerge, in most cases, to identify factors which influence the performance of the assessed units, inevitably reflected in the available data."

Remember also that the measure of the efficiency of a unit must be a monotonically decreasing function of the inputs, i.e, ceteris paribus, efficiency increases when an input decreases (and vice versa). We can also say that this measure should be a monotonically increasing function of the outputs, i.e, an increase in output to 
produce, ceteris paribus, an increase in the measure of performance.

Experts in the superior education area intervened in the definition of the variables, and pointed out a certain amount of attributes to be considered when analyzing the efficiency of the academic units.

Subsequently, with the help of correlation statistical techniques, it was possible to reduce the number of variables to be included in the study.

The following are the final selected variables, whose data for the 2007- 2011 period was obtained from the Statistical Yearbook of the UNC.

INPUTS:

Non-teaching Staff: amount of support personnel in each AU.

EDE Teachers: number of full-time teachers in each AU.

The EDE Teachers variable is calculated as follows: full-time teachers $+0,5$ part-time teachers $+0,25$ simple dedication teachers.

\section{OUTPUTS:}

Students: amount of degree students in each AU.

Proy_SeCyT: total of research projects certified by Science and Technology Secretariat in each AU.

Undergraduate degrees: number of undergraduate degrees offered by each AU.

DECISION MAKING UNITS (DMUS):

Faculty of Architecture

Faculty of Sciences

Faculty of Chemistry

Faculty of Mathematics, Astronomy y Physics (FaMAF)

Faculty of Agricultural Sciences

Faculty of Medicine

Faculty of Odontology

Faculty of Law and Social Sciences

Faculty of Economics

Faculty of Philosophy and Humanities

Faculty of Psychology

Faculty of Languages

It must be said that the Faculty of Arts is not included in this analysis, because it is relatively new so there is not complete data in the consulted sources.

\section{Application of the DEA model}

The efficiency indexes obtained for each AU are shown in Table 1, while the evolution of efficiency is presented in graphic 1 .

The results allowed the identification of the evolution of efficiency in each AU during the analyzed term and show an incremental tendency in average indexes. In this line of evolution, the Faculty of Economics and the Faculty of Law and Social Sciences can be highlighted. The number of efficient AU has also increased.
Table 1: Efficiency Scores

\begin{tabular}{|c|c|c|c|}
\hline \multirow{2}{*}{ DMUs } & \multicolumn{3}{|c|}{ Scores } \\
\hline & 2007 & 2009 & 2011 \\
\hline Faculty of Psychology & 100,00 & 100,00 & 100,00 \\
\hline Faculty of Languages & 100,00 & 100,00 & 100,00 \\
\hline FaMAF & 100,00 & 100,00 & 100,00 \\
\hline Faculty of Chemistry & 100,00 & 100,00 & 100,00 \\
\hline F. of Philosophy and Humanities & 85,85 & 100,00 & 100,00 \\
\hline Faculty of Economics & 75,45 & 79,18 & 99,19 \\
\hline Faculty of Agricultural Sciences & 71,79 & 59,38 & 70,19 \\
\hline Faculty of Sciences & 55,08 & 72,62 & 47,15 \\
\hline Faculty of Law and Social Sciences & 51,79 & 60,59 & 87,76 \\
\hline Faculty of Architecture & 45,07 & 40,69 & 36,86 \\
\hline Faculty of Odontology & 33,76 & 32,81 & 36,19 \\
\hline Faculty of Medicine & 30,90 & 33,02 & 26,35 \\
\hline Average efficiency : & $70,81^{\top}$ & $73,19^{\top}$ & 75,31 \\
\hline
\end{tabular}

Graphic 1: Evolution of efficiency

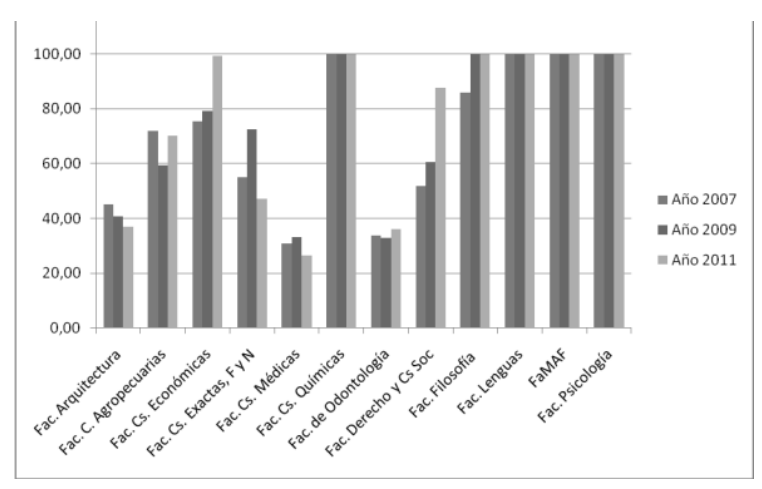

Graphic 2: Variable comparison between Fac. of Odontology and Fac. of Chemistry

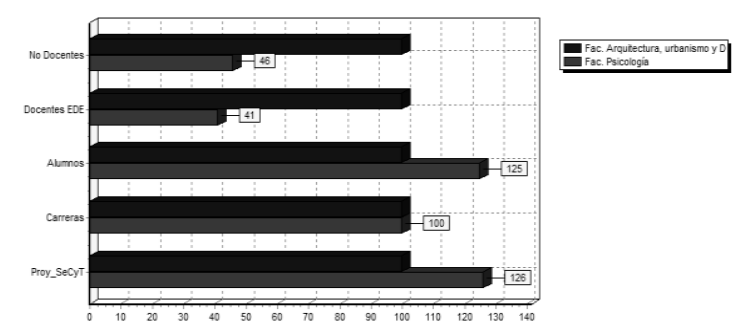

Graphic 3: Variable comparison between Fac. of Architecture and Fac. of Psychology

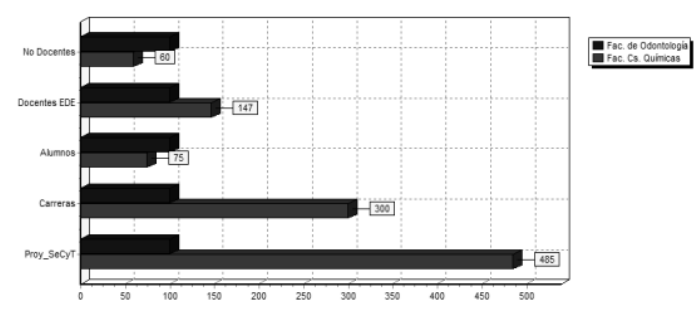


Graphic 4: Potential increasing. Faculty of Architecture

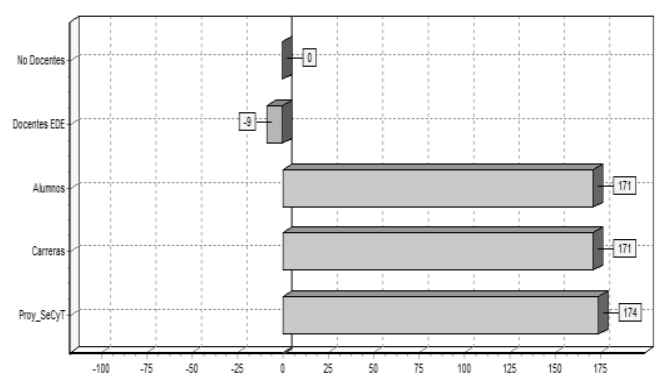

Graphic 5: Potential increasing. Faculty of Odontology

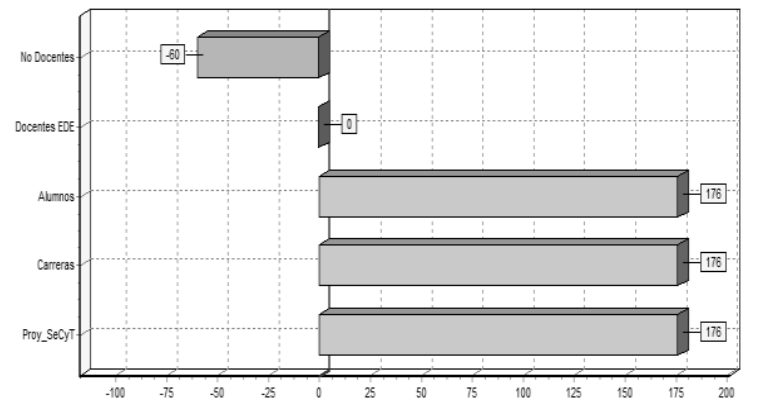

Among the results, the following deserve to be underlined:

- Faculties of Languages; Psychology; Chemistry and FaMAF were efficient in all the analyzed years.

- Faculty of Philosophy and Humanities improved its performance, being efficient in 2009 and 2011.

- Indexes achieved by the Faculties of Architecture; Odontology and Medicine were lower than the average for all years.

From the information obtained by applying the DEA model, certain guidelines can be given to improve each AU in particular and the University as a whole. As an example some of the inefficient units are examined. In 2011 the Faculty of Architecture achieved a 36,90\% index; graphic 2 compares the values of its input and output variables with those of the Faculty of Psychology, which is located on the efficiency frontier (100\% index). It is possible to observe that the inefficient unit with much more resources (teachers and non-teaching staff) attended less students and it has less research projects. A similar analysis is presented in graphic 3 in relation to the Faculty of Odontology $(36,20 \%$ index) and the Faculty of Chemistry (100\% index). Meanwhile, grafics 4 and 5 show the potential improvements of both inefficient academic units, i.e. suggestions regarding input reduction and output increasing which should be carried out in order to situate them on the efficiency frontier. This information might be extremely useful for the purposes of decision-making processes, to be taken into account either for budget allocations or resource reassignments between the different units.

\section{Conclusions}

This paper presents an analysis of the actual situation in the Universidad Nacional de Córdoba, with regard to the use of teaching and non-teching staff resources in each academic unit from the perspective of the efficiency with which they are being used. The sum of students, undergraduate degrees and research projects were considered. The information provided by the model in relation to each AU state of affairs contributes a clearer and more objective point of view for decision-makers when defining politics that involve the different AU. Moreover, it manifests the existing heterogeneity inside the twelve AU regarding number of students, research activity and amount of undergraduate degrees. For this reason, it would be interesting to broaden this study using additional DEA models, which would allow including the effects of the efficiency scale (Banker, Cooper and Rhodes, 1984) and to consider the presence of non-discretional inputs (Banker and Morey, 1986).

\section{Bibliography}

Statistical Yearbook of the Universidad Nacional de Córdoba. 2007-2011.

http://www.unc.edu.ar/estudios/programassaa/estadisticas/anuarios. $10 / 02 / 2012$.

[1] Avkiran N. (2001): "Investigating technical and scale efficiencies of Australian Universities through Data Envelopment Analysis". Socio Economic Planning Sciences, vol. 35, pp. 57-80.

[2] Banker, R. D., Charnes, A. and Cooper, W. W. (1984): Some Models for Estimating Technical and Scale Inefficiencies in Data Envelopment Analysis. Management Science, vol. 30 (9), pp. 1078-1092.

[3] Banker R. and Morey R. (1986): "Efficiency Analysis fir Exogenously Fixed Inputs and Outputs". Operations Research 34. pp. 513-521.

[4] Bifulco R. and Bretschneider S. (2001): "Estimating School Efficiency. A Comparison of Methods Using Simulated Date". Economics of Education Review, pp. 417-429.

[5] Charnes, A., Cooper, W. W. and Rhodes, E. (1978): "Measuring the Efficiency of Decision Making Units". European Journal of Operational Research 2, pp. 429444.

[6] Cook W. and Seiford L. (2009): "Data Envelopment Analysis (DEA)-Thirty years on". European Journal of Operational Research 192 (2009) pp.1-17.

[7] Cooper, W. W., Seiford, L. y Tone, K. (2007). "Data envelopment analysis: a comprehensive text with models, applications, references and DEA-solver software". New York, N.Y. Springer, Second Edition.

[8] Lindsay, A. (1981): "Assesing Institucional Performance in Higher Educations: A Managerial Perspective". Higher Education, Vol. 10, pp. 687-706.

[9] Stern Z., Mehrez A. and Barboy A. (1994): "Academics Departments Efficiency via DEA". 
Computers and Operations Research 21 (5), pp. 543556.

[10] Tomkins C. and Green R. (1988): “An Experiment in the Use of Data Envelopment Analysis for Evaluating the Efficiency of UK University Departaments of Accounting". Financial Accountability and Management, vol. 4 (2), pp. 147-165.

[11] Thanassoulis, E. (2001): "Introduction to the theory and application of data envelopment analysis: a foundation text with integrated software. Norwell, Mass. Kluwer Academic Publishers. 